\title{
Global Challenges for our Common Future: a Paleoscience Perspective
}

\author{
Blas Valero-Garcés', A. Moreno', P. González-Sampériz1, G. Gil-Romera' and Local \\ Organizing Committee ${ }^{2}$
}

PAGES Open Science Meeting, Zaragoza, Spain, 9-13 May 2017

The PAGES community met in Zaragoza, Spain, in May 2017 for the 5th Open Science Meeting (OSM). The meeting was organized by the Pyrenean Institute of Ecology, a research center of the Spanish National Research Council, with the collaboration of the University of Zaragoza. The city of Zaragoza is famous for the World Heritage Mudejar architecture, a syncretic art developed in the Christian kingdoms by Muslim artisans. The Mudejar star, the 2017 OSM logo, was chosen as a reminder of the positive outcomes when diverse minds and cultures meet.

Over 900 delegates (44\% female) from 56 countries participated in 33 sessions (with up to six parallel sessions). In total, more than 980 communications were presented as posters (646) and talks (338). In addition, nine PAGES and affiliated working groups had meetings before, during and after the OSM. Lunch was served in the Auditorium to all participants in a wifi-free environment to promote interactions, sharing of new ideas, and some relaxation after the intense morning sessions. Science and Somontano wine helped to maintain lively discussions during the poster sessions.

Eight plenary speakers gave us the stateof-the-art in ocean warming (Nerilie Abram, Australia), geoinformatics (Julien EmileGeay, USA), climate system variability (Gabriele Hegerl, UK), climate evolution of the Western Mediterranean (Isabel Cacho, Spain), interglacials (Erik Wolff, UK), greenhouse gases variability (Ed Brook, USA), human evolution and climate (Juan Luis Arsuaga, Spain) and the interactions of climate, vegetation and humans in the Iberian Peninsula (Penélope GonzálezSampériz, Spain).

The meeting structure, with its 33 sessions, was built around PAGES' scientific themes of climate, environment and humans. Also well represented were the strengthened connections between PAGES working groups and the increasing importance of interdisciplinary approaches in paleoscience. Particularly well attended were the sessions on the Southern Hemisphere, the Mediterranean, the climate of the last two millennia (2k) and Quaternary interglacials.

The Local Organizing Committee organized two outreach events: A film night with Leonardo DiCaprio's climate change documentary "Before the Flood"; and a Round Table, open to the public and led by politicians and scientists, on the topic "Climate change: from global to local challenges."

Social activities included the ice breaker with music by the O'Carolan Quintet, the conference dinner with subsequent disco, and a free visit to the Aljafería Palace. After the long scientific sessions, delegates strolled the city parks and the Ebro River, enjoyed light tapas dinners in bars and terraces downtown, and visited the museums and old buildings to get a taste of the city's rich culture. Four teams, representing modelers and proxies, played in the traditional PAGES Cup football (soccer) match, held in the José Antonio Labordeta Park. In spite of cloudy skies and mosquitoes, free beer and enthusiastic fans kept the sport spirit high (Ashastina and Alexandroff 2017).
For a few days, paleoscientists flooded Zaragoza and made the headlines in local and regional media coverage; see a selection of the many TV and print reports here: www.pages-osm.org/osm/ post-meeting-material/pages17-media

Field trips were conducted to the OrdesaMonte Perdido National Park to illustrate some of the glacial features; to the Segre River and its unique paleoflood record, and to the Huerva River to show the geoarchaeology of the region.

We thank all supporters, sponsors and volunteers who helped organize and finance the 5th PAGES OSM meeting. In these times of rapid change, the OSM showcased how our science is more useful than ever for society - from citizens to politicians. We thank all the attendants for presenting their science, participating in the discussions and field trips and creating links to strengthen PAGES as a global community. We wish you all a very productive, fruitful and inspiring period to face together the challenges ahead of us until the PAGES OSM convenes again in four years.

\section{AFFILIATIONS}

'Pyrenean Institute of Ecology, Spanish National Research Council, Zaragoza, Spain

${ }^{2}$ www.pages-osm.org/osm/organizational-structure

\section{CONTACT}

Blas Valero-Garcés: blas@ipe.csic.es

\section{REFERENCES}

Ashastina K, Alexandroff S (2017) PAGES Mag 25(2): 107

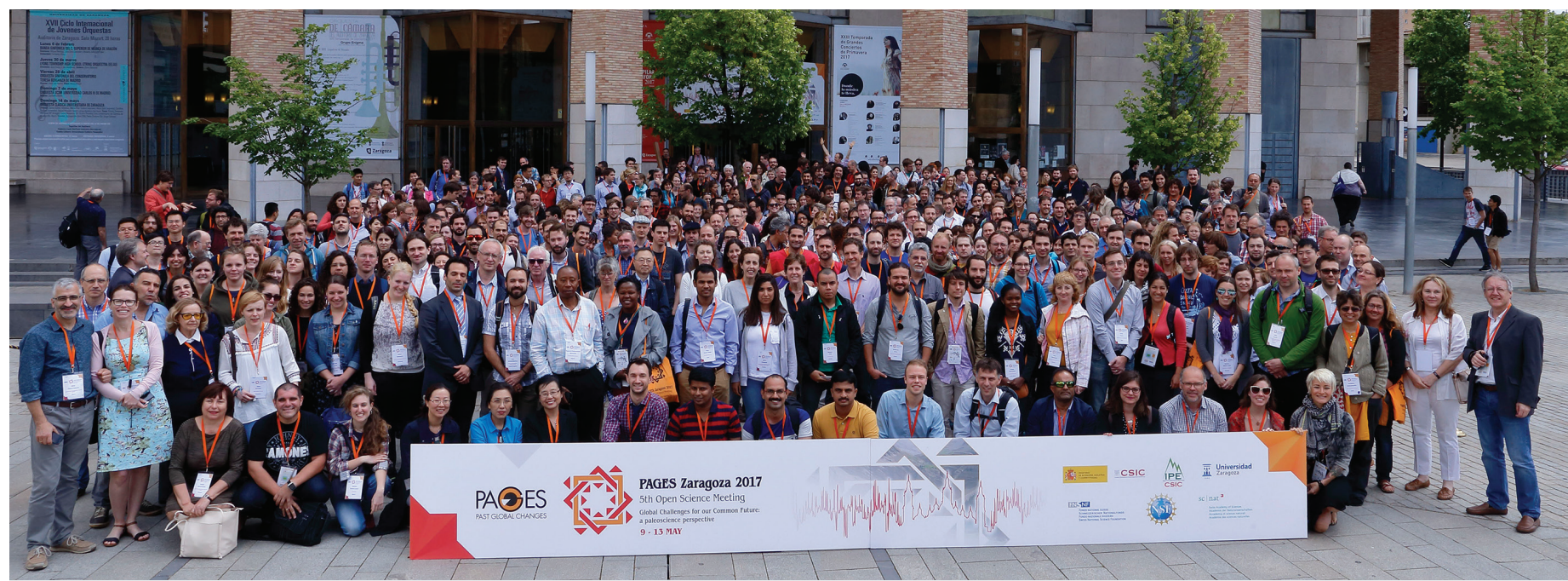

Figure 1: Subset of the over 900 OSM participants in front of the venue in Zaragoza, Spain. 